(C) 2019, The Authors. Published by FASS Inc. and Elsevier Inc. on behalf of the American Dairy Science Association ${ }^{\circledR}$. This is an open access article under the CC BY-NC-ND license (http://creativecommons.org/licenses/by-nc-nd/4.0/).

\title{
Effect of energy source in calf milk replacer on performance, digestibility, and gut permeability in rearing calves
}

\author{
L. Amado, ${ }^{1 *}$ H. Berends, ${ }^{1}$ L. N. Leal, ${ }^{1}$ J. Wilms, ${ }^{1}$ H. Van Laar, ${ }^{1,2}$ W. J. J. Gerrits, ${ }^{2}$ and J. Martín-Tereso ${ }^{1}$ \\ ${ }^{1}$ Trouw Nutrition Research and Development, P.O. Box 299, 3800 AG Amersfoort, the Netherlands \\ ${ }^{2}$ Animal Nutrition Group, Wageningen University, P.O. Box 338, $6700 \mathrm{AH}$ Wageningen, the Netherlands
}

\section{ABSTRACT}

Current calf milk replacer (CMR) compositions significantly differ from whole milk in their levels of energy, protein, and minerals. Energy source is one of the major differences, as CMR contains high levels of lactose, whereas whole milk contains higher levels of fat. The aim of this study was to determine the effect of partially exchanging lactose for fat on performance, digestibility, and gut permeability in calves fed twice daily on a high feeding plane. Lactose and fat were exchanged in the CMR formulation on a weight-weight basis. The $\mathrm{CMR}$ were isonitrogenous but not isoenergetic. A total of 60 male Holstein-Friesian calves were assigned to 1 of 30 blocks based on serum $\operatorname{IgG}$, body weight, and date of collection after birth. Within each block, calves were randomly assigned to 1 of 2 treatments: high fat and high lactose. The CMR was provided twice daily until $49 \mathrm{~d}$ of age, followed by a gradual weaning period of $14 \mathrm{~d}$. Starter, straw, and water were available ad libitum throughout the complete study. Exchanging lactose for fat did not affect growth; intakes of starter, straw, water, crude protein, or total energy; or apparent total-tract digestibility of nutrients. Gastrointestinal permeability was assessed by measuring the recovery of lactulose and $\mathrm{Cr}$ in 24-h urine and the $\mathrm{Cr}$ concentration and lactulose:D-mannitol ratio in serum following an oral pulse dose. Urinary recoveries of $\mathrm{Cr}$ and lactulose were generally low in both treatments but were higher in calves fed the high-fat CMR. Accordingly, the serum lactulose:D-mannitol ratio and serum $\mathrm{Cr}$ concentrations were higher in calves fed the high-fat CMR. In wk 1 and during the weaning transition, calves fed the highfat CMR had significantly fewer abnormal fecal scores. In conclusion, exchanging lactose for fat in the CMR did not affect growth performance, total feed intake, or nutrient digestibility. The high-fat CMR was associated

\footnotetext{
Received October 15, 2018.

Accepted January 10, 2019

*Corresponding author: liliana.amado.barrantes@trouwnutrition
} .com with an increase in permeability markers but positively influenced fecal scores in calves.

Key words: calf milk replacer, lactose, fat, gut permeability

\section{INTRODUCTION}

The current global trend in dairy calf rearing is to focus on growth performance using whole milk (WM) or calf milk replacers (CMR) of high nutritional quality. This is the consequence of recent insights suggesting that nutrient intake from WM or CMR during the preweaning period improves future milk yield (Moallem et al., 2010; Bach, 2012; Soberon et al., 2012). Feeding elevated levels of milk ( $\sim 20 \%$ of birth weight by volume) to calves improves health, growth rates, feed efficiency, and lifetime production (Soberon et al., 2012). Despite economic consequences on farm milk output, many farmers are adopting this strategy using WM. This choice is generally motivated by the availability of WM on farm and by the fact that the nutrient balance of CMR significantly differs from that of WM. Compared with most commercial CMR, WM has higher energy content and contains bioactive components such as enzymes, hormones, and growth factors (Lee et al., 2009; Araujo and Bach, 2015). Compositional differences may result in increased BW at weaning, with some indications of long-term benefits on future milk production (Shamay et al., 2005; Moallem et al., 2010).

Commercial CMR usually contain higher levels of lactose ( $42-45 \%$ vs. $35 \%$, DM basis) and lower levels of fat (16-20\% vs. 30\%, DM basis) than WM (Hof, 1980; Park, 2009). Furthermore, WM contains about 5.4 Mcal of $\mathrm{ME} / \mathrm{kg}$ of DM, whereas commercial CMR products range between 4.6 and $4.7 \mathrm{Mcal}$ of $\mathrm{ME} / \mathrm{kg}$ of DM, indicating that CMR provides lower ME when fed at similar rates (Drackley, 2008). Typical commercial CMR formulations range from 20 to $28 \%$ of $\mathrm{CP}$ (Bartlett et al., 2006; Bascom et al., 2007; Hill et al., 2010), resulting in a lower energy:protein ratio compared with WM. Furthermore, CMR has a higher ash content, particularly when it consists of mineral-rich 
dairy by-products. In addition, energy type and content in CMR may affect the osmolality of the solution (Wilms et al., 2019).

To compensate for differences in energy supply between WM and CMR, several strategies have been used to accelerate the growth rate of calves during the milk phase. These strategies include higher feeding rates or modifying the milk replacer composition to increase nutrient intake (Silva et al., 2015). The CP and energy intake from specific CMR formulations strongly influences calf ADG (Bartlett et al., 2006). When CP is restricted or limited relative to energy intake, the extra energy is stored as fat (Hill et al., 2009). Several studies show that increasing the fat content in CMR can affect growth and performance of calves (Bartlett et al., 2006; Bascom et al., 2007; Hill et al., 2008). These studies show increased fat deposition in response to higher fat inclusion in CMR (Tikofsky et al., 2001). Whether fat deposition (within certain boundaries) is beneficial or detrimental remains an open question. Increased energy intake of calves in the first 2 mo of life showed no negative effects on subsequent milk production at maturity (Brown et al., 2005), whereas fat deposition during the preweaning period may play a beneficial role in mitigating weaning stress in calves (Lee et al., 2009). Standard CMR formulations and lower feeding rates do not provide sufficient nutrients for the calf, which may influence immune function and disease susceptibility (Nonnecke et al., 2003).

Our hypothesis was that a weight-weight exchange of lactose for fat in CMR would positively affect performance and gastrointestinal health in rearing calves fed twice daily. To this end, the objective of the current study was to investigate the effects of exchanging dietary energy sources (fat vs. lactose) on growth performance, intestinal permeability, digestibility, and fecal score consistency in rearing calves.

\section{MATERIALS AND METHODS}

This study was conducted between January and May 2017 at the Calf Research Facility of Trouw Nutrition Research and Development (Sint Anthonis, the Netherlands). All procedures described in this article complied with the Dutch Law on Experimental Animals, which complies with ETS123 (Council of Europe 1985 and the 86/609/EEC Directive), and were approved by the animal welfare authority (DEC Utrecht, the Netherlands).

\section{Animals, Housing, and Feeding}

A total of 60 male calves between 0 and $3 \mathrm{~d}$ of age were collected from local dairy farms at a maximum distance of $14 \mathrm{~km}$ from the calf research facility. At the farm of origin a standardized protocol for colostrum management was followed wherein calves were fed $3 \mathrm{~L}$ within the first $3 \mathrm{~h}$ after birth followed by 2 feedings of $2 \mathrm{~L}$ for a total of 3 feedings of colostrum in the first $24 \mathrm{~h}$ of life. Successful application of this protocol was monitored by assessment of blood IgG within 48 to 72 $\mathrm{h}$ after birth of the calf at arrival at the research facility. Following colostrum feeding, calves were provided meals of $2.5 \mathrm{~L}$ of a CMR containing $150 \mathrm{~g}$ of $\mathrm{CMR} / \mathrm{L}$ (Sprayfo Excellent, Trouw Nutrition, Deventer, the Netherlands) twice daily up to d 3 of life. Calves were assigned to 1 of 30 blocks ( 2 calves per block) based on IgG category (low: 1,000-2,000 mg/dL; high: $>2,000$ $\mathrm{mg} / \mathrm{dL}$; NAHMS, 2007), day of arrival, and BW. Mean BW upon arrival was $44.7 \pm 0.86 \mathrm{~kg}$ and $45.5 \pm 0.82$ $\mathrm{kg}$ and serum IgG concentration was $1.871 \pm 121 \mathrm{mg} /$ $\mathrm{dL}$ and $2.003 \pm 122 \mathrm{mg} / \mathrm{dL}$ for the high-fat $(\mathbf{H F})$ and high-lactose (HL) treatments, respectively. Within each block, calves were randomized using the RAND function in Microsoft Excel (Microsoft Corp., Redmond, WA) to 1 of 2 isonitrogenous liquid feed treatments. Calves selected for the study were considered healthy after physical examination. Calves were housed indoors in individual pens $(1.22 \times 2.13 \mathrm{~m})$, separated by galvanized bar fences, and equipped with $50 \%$ rubber-slatted floors in the front and $50 \%$ lying area, including a mattress covered with flax straw, in the back. Milk replacer was reconstituted with water and supplied in a teat bucket at $40^{\circ} \mathrm{C}$. Milk replacer concentration was 150 $\mathrm{g} / \mathrm{L}$ and was provided daily in 2 equally sized meals at 0700 and $1600 \mathrm{~h}$ (Table 1). Meal size was $3.0 \mathrm{~L}$ until $14 \mathrm{~d}$ of age, increased to $3.5 \mathrm{~L}$ between 14 and $49 \mathrm{~d}$ of age, decreased to $2.5 \mathrm{~L}$ between 49 and $56 \mathrm{~d}$ of age, and decreased further to $1.5 \mathrm{~L}$ between 57 and $63 \mathrm{~d}$ of age. Calves had ad libitum access to water, chopped wheat straw (3-7 cm chop length; Ruwvoer Distributiecentrum, Gassel, the Netherlands), and starter feed (Table 1; ForFarmers, Lochem, the Netherlands), all of which were provided in separate buckets.

Calves were fed 1 of 2 experimental diets with an HF or HL milk replacer. Fat and lactose were exchanged on a 1:1 (wt/wt) basis (gram-per-gram substitution), subsequently altering energy content. The experimental diets were therefore isonitrogenous but not isoenergetic, whereas the rest of the CMR formulation remained unchanged. Nutrient composition of the diets is shown in Table 1. The experiment was designed to contrast an increase of crude fat from 17.3 to $23.3 \%$ associated with a reduction of lactose from 44.3 to $37.3 \%$. The starter concentrate had $20 \% \mathrm{CP}$ and $3.8 \%$ crude fat.

The minimum temperature in the calf facility was maintained at $15^{\circ} \mathrm{C}$, and relative humidity was below 
Table 1. Analyzed and estimated nutrient composition ( $\mathrm{g} / \mathrm{kg}$ of DM unless noted) of feeds used in the study

\begin{tabular}{|c|c|c|c|c|}
\hline \multirow[b]{2}{*}{ Item } & \multicolumn{2}{|c|}{ Milk replacer } & \multirow[b]{2}{*}{ Concentrate } & \multirow[b]{2}{*}{ Straw } \\
\hline & High fat & High lactose & & \\
\hline DM, $\mathrm{g} / \mathrm{kg}$ of product & 970 & 968 & 874 & 936 \\
\hline $\mathrm{CP}$ & 235 & 232 & 204 & 54 \\
\hline Crude fat & 233 & 173 & 38 & 11 \\
\hline Lactose & 373 & 443 & - & - \\
\hline Crude ash & 78 & 79 & 88 & 62 \\
\hline Starch & - & - & 241 & 8 \\
\hline $\mathrm{ME},{ }^{1} \mathrm{Mcal} / \mathrm{kg}$ & 4.7 & 4.4 & 3.3 & - \\
\hline CP:ME ratio & 50.1 & 53.1 & 62.8 & - \\
\hline $\mathrm{Na}$ & 7.1 & 6.9 & 4.7 & 460 \\
\hline $\mathrm{K}$ & 20 & 21.2 & 16 & 14.8 \\
\hline $\mathrm{Ca}$ & 8.9 & 8.8 & 13.8 & 3.1 \\
\hline $\mathrm{P}$ & 6.8 & 6.9 & 4.8 & 1.1 \\
\hline $\mathrm{Cl}$ & 13 & 14 & 4.8 & 2.5 \\
\hline
\end{tabular}

${ }^{1}$ Calculated following NRC (2001).

$80 \%$. Calves were exposed to daylight and artificial light from 0600 to $2200 \mathrm{~h}$ and to a night light during the remainder of the $24-\mathrm{h}$ cycle.

\section{Measurements}

Health was monitored daily by caretakers, and a standard veterinary protocol was followed in case of disease. A veterinarian was consulted if the symptoms were not described in the standard protocol. Body weight was measured on the day of arrival and once per week thereafter until $10 \mathrm{wk}$ of age. Individual intakes of milk replacer, water, concentrate, and straw were weighed and recorded daily during the entire experiment.

Total fecal collection was conducted for $48 \mathrm{~h}$ in 10 randomly selected blocks of calves ranging from 24 to $35 \mathrm{~d}$ of age. Feces were collected using fecal bags glued to the hindquarters of the animal. Fecal samples were analyzed for DM, CP, crude fat, ash, VFA, and mineral profile ( $\mathrm{Ca}, \mathrm{P}, \mathrm{Na}$, and $\mathrm{K})$.

Gastrointestinal permeability was assessed in the same group of calves by measuring the appearance of indigestible markers in urine. Lactulose $(0.4 \mathrm{~g} / \mathrm{kg}$ of BW; Sigma-Aldrich, Zwijndrecht, the Netherlands), D-mannitol (0.12 g/kg of BW; Sigma-Aldrich), and Cr-EDTA $(0.1 \mathrm{~g} / \mathrm{kg}$ of BW; Masterlab, Boxmeer, the Netherlands) were dissolved separately in $100 \mathrm{~mL}$ of warm water. The solution was mixed together with the CMR meal at $0630 \mathrm{~h}$. Calves were allowed to consume their meal for a maximum of $15 \mathrm{~min}$. Urine was quantitatively collected during $24 \mathrm{~h}$ starting right after marker administration. A urine bag was glued to the underside of the calf, and bags were connected with a tube to a bucket. Urine was directly acidified to $\mathrm{pH}$ $\leq 2$ with sulfuric acid to prevent microbial degradation.
Urine samples were analyzed for lactulose and Cr. For technical reasons, D-mannitol analysis in urine was not successful. Calves were fit with jugular catheters (Intraflon 2 13G, Ecouen, France) on the day before scheduled blood sample collection. Samples were obtained at $0,30,60,90,120,150,180,210,240,300,360$, and 420 min relative to marker administration. The catheters were flushed with $2 \mathrm{~mL}$ of heparinized saline $(2 \%$ solution) before and after sample collection. Blood samples were collected using 20-mL syringes and then allocated into a potassium EDTA Vacutainer (Becton Dickinson, Franklin Lakes, NJ) and a sodium fluoride Vacutainer that contained a glycolysis inhibitor. All blood samples were centrifuged immediately at 2,800 $\times g$ for $30 \mathrm{~min}$ at room temperature, and $1.5 \mathrm{~mL}$ of plasma was pipetted into 2-mL cryotubes and stored immediately at $-20^{\circ} \mathrm{C}$. Blood samples were analyzed for $\mathrm{Cr}$, lactulose, and Dmannitol.

All study personnel involved in calf handling and taking measurements were blinded to the treatments. Photos of feces were taken daily for all calves, and fecal scores were evaluated at the end of the study by a single observer who was blinded to treatments. The scoring system included 4 categories where 0 was considered normal and 3 was extremely loose. Fecal scores $\geq 2$ were considered abnormal. Medical treatments were recorded daily.

\section{Chemical Analysis}

The feeds and feces were analyzed for DM content by drying to a constant weight in a $103^{\circ} \mathrm{C}$ stove for $4 \mathrm{~h}$ (EC 152/2009; EC, 2009). Crude protein was analyzed by combustion according to the Dumas method (Etheridge et al., 1998). Crude fat content was determined by treating the sample with hydrochloric acid and then 
extracting with petroleum (EC 152/2009; EC, 2009). Starch content was determined enzymatically as described by Rijnen et al. (2001). Crude ash content was analyzed by incineration in a muffle furnace by combustion for $4 \mathrm{~h}$ at $550^{\circ} \mathrm{C}$ (EC 152/2009; EC, 2009). Mineral profile (milk replacer and feces) was determined using inductively coupled plasma MS (PerkinElmer ICP-MS 300D, PerkinElmer, Waltham, MA) according to NENEN 15510 (European Union, 2017).

For the preparation of $\mathrm{Cr}$ measurements, $0.5 \mathrm{~mL}$ of nitric acid was added to $1 \mathrm{~mL}$ of urine sample. After 4-h incubation at $95^{\circ} \mathrm{C}$, MilliQ water (Millipore, Billerica, MA) was added to the solution until a final volume of $15 \mathrm{~mL}$ was reached. Samples were analyzed by inductively coupled plasma MS (PerkinElmer ICPMS 300D, Waltham, MA). For the quantification of samples, a calibration curve of $\mathrm{Cr}(0,0.005,0.02,0.1$, and $0.5 \mathrm{mg} / \mathrm{L}$ ) was used, and the results were corrected using an internal standard (germanium 74). For the extraction of D-mannitol and lactulose, urine samples were diluted using maltitol as the internal standard. These extracts were then analyzed using a Phenomenex Luna 5u NH2 RP 18 250-mm $\times$ 4.6-mm column (Phenomenex, Utrecht, the Netherlands) on a Thermo Endura liquid chromatography tandem mass spectrometer (heated electrospray ionization source) with an Ultimate 3000 pump and autosampler (Thermo Fisher Scientific, Waltham, MA). The elution buffer was a blend of $75 \%$ acetonitrile and $25 \%$ water containing $1 \mathrm{mmol} / \mathrm{L}$ formiate.

\section{Calculations and Statistical Analysis}

A classical power analysis was conducted to determine the number of experimental units needed. The power $(1-\beta)$ was chosen to be equal to $80 \%$. The $\alpha$-level was 0.05 . Growth performance was considered the most reliable parameter to determine power. Based on a previous study conducted at the same research facility (Calf and Beef Research, Sint Anthonis, the Netherlands) for $57 \mathrm{~d}$ after arrival at 0 to $3 \mathrm{~d}$ of age, a standard deviation of $100 \mathrm{~g} / \mathrm{d}$ was assumed. The minimal meaningful difference in ADG was considered to be $75 \mathrm{~g} / \mathrm{d}$. The minimal sample size was 30 calves per treatment when accounting for a maximum mortality rate of $10 \%$.

All statistical analyses were performed using SAS Studio (version 3.2, SAS Institute Inc., Cary, NC). Data on growth, intakes, and plasma concentrations of $\mathrm{Cr}$, lactulose, and mannitol were analyzed with a mixed model procedure (PROC MIXED). Binary data (fecal score) were analyzed following a binomial distribution and proportions (apparent total-tract digestibility, minerals, and excretion in urine of $\mathrm{Cr}$ and lactulose) with a $\beta$-distribution using a generalized linear mixed model (PROC GLIMMIX).

In all analyses, the individual calf was considered as experimental unit with treatment and block as fixed and random effects, respectively. Time entered the model as a repeated statement in case of repeated measurements, and then the interaction between time and treatment and the SLICE command from SAS Studio (version 3.2, SAS Institute Inc.) to control type I error were included. Treatment averages were presented as least squares means and standard errors of the mean. Significance was declared when $P \leq 0.05$, and trends were declared when $P<0.10$.

\section{RESULTS}

The data set included 52 successful observations (24 calves in the HL treatment and 28 calves in the HF treatment). In total, 8 calves were not included in the data analysis based on the pre-established exclusion criteria for health (3 clinically sick calves, defined by a veterinarian, were excluded because therapeutic treatments may invalidate the results) or feed refusals (5 calves were excluded when they refused 3 or more consecutive CMR meals).

Body weight was not affected by dietary treatment at any time point (Table 2). Similarly, ADG (Table 2) remained unaffected by treatment. Total milk replacer intakes were also equal between dietary treatments (Table 2). Starter intake was higher during wk 7 to 9 for HL calves but was equal for the total course of the study (Table 2). Straw intake did not differ between the CMR treatments (Table 2). Metabolizable energy intake was identical between treatments over the entire experiment. However, intake of specific dietary constituents was different in that there was an increase of $13 \mathrm{MCal}$ of $\mathrm{ME} / \mathrm{d}$ from CMR $(P<0.001)$ and a numerically lower $(13 \mathrm{MCal} / \mathrm{d}, P=0.19)$ starter intake in the HF group. Crude protein and water intake did not differ between treatments (Table 2).

The apparent digestibility of DM, CP, fat, and ash was not different between treatments (Table 3). The apparent total-tract digestibility of $\mathrm{Ca}, \mathrm{P}$, and $\mathrm{K}$ in feces was not different, but it was higher for $\mathrm{Na}$ in the HL calves $(P<0.05$; Table 3$)$.

The 24-h urinary recovery of lactulose was lower $(P$ $<0.05)$ with the HL treatment compared with the HF treatment at 1.4 and $2.2 \%$ of the oral dose, respectively (Table 4). The urinary recovery of Cr was $3.3 \%$ lower with HL compared with $4.6 \%$ in the HF group $(P<$ $0.05)$. No treatment effects were found in the 6-h urinary recovery of lactulose and $\mathrm{Cr}$.

Serum Cr concentrations and lactulose:D-mannitol ratio were lower $(P<0.01)$ for HL calves than for HF 
Table 2. The effect of exchanging fat for lactose in a calf milk replacer (CMR) on BW gain and intakes of $\mathrm{CMR}$, total CP, total ME, starter, straw, and water (LSM) in calves during the first 10 wk of age

\begin{tabular}{|c|c|c|c|c|c|c|}
\hline \multirow[b]{2}{*}{ Item } & \multicolumn{4}{|c|}{ Treatment } & \multicolumn{2}{|c|}{$P$-value } \\
\hline & $\begin{array}{l}\text { High fat } \\
(\mathrm{n}=28)\end{array}$ & SEM & $\begin{array}{l}\text { High lactose } \\
\quad(\mathrm{n}=24)\end{array}$ & SEM & $\mathrm{T}^{1}$ & $\mathrm{~T} \times$ time \\
\hline \multicolumn{7}{|l|}{$\mathrm{BW}, \mathrm{kg}$} \\
\hline Arrival & 44.7 & 0.86 & 45.5 & 0.82 & 0.50 & - \\
\hline Wk 10 & 98.4 & 1.9 & 99.7 & 1.8 & 0.60 & - \\
\hline $\mathrm{ADG}, \mathrm{kg} / \mathrm{d}$ & 0.64 & 0.02 & 0.66 & 0.02 & 0.42 & 0.35 \\
\hline \multicolumn{7}{|l|}{ Total intake } \\
\hline $\mathrm{CMR}, \mathrm{kg}$ of DM & 57.2 & 0.3 & 57.7 & 0.3 & 0.35 & 0.07 \\
\hline Starter, $\mathrm{kg}$ of DM & 41.3 & 2.6 & 46.1 & 2.4 & 0.22 & 0.15 \\
\hline Straw, $\mathrm{kg}$ of DM & 0.84 & 0.16 & 0.80 & 0.15 & 0.78 & 0.12 \\
\hline Water, kg & 226.7 & 18.5 & 230.9 & 17.1 & 0.87 & 0.01 \\
\hline \multicolumn{7}{|l|}{ ME intake, Mcal } \\
\hline From CMR & 264 & 1.5 & 250 & 1.4 & $<0.01$ & - \\
\hline From starter & 117 & 7.3 & 131 & 6.8 & 0.19 & - \\
\hline Total & 381 & 8.0 & 381 & 7.4 & 0.84 & 0.18 \\
\hline \multicolumn{7}{|l|}{$\mathrm{CP}$ intake, $\mathrm{kg}$} \\
\hline From CMR & 13.0 & 0.08 & 13.1 & 0.07 & 0.35 & - \\
\hline From starter & 8.4 & 0.53 & 9.4 & 0.48 & 0.14 & - \\
\hline Total & 21.5 & 0.56 & 22.5 & 0.51 & 0.17 & - \\
\hline
\end{tabular}

${ }^{1} \mathrm{~T}=$ effect of treatment.

Table 3. The effect of exchanging fat for lactose in a calf milk replacer on apparent total-tract digestibility of nutrients (LSM) in calves measured at 4 wk of age

\begin{tabular}{lccccc}
\hline & \multicolumn{4}{c}{ Treatment } \\
\cline { 2 - 4 } Item & $\begin{array}{c}\text { High fat } \\
(\mathrm{n}=9)\end{array}$ & SEM & $\begin{array}{c}\text { High lactose } \\
(\mathrm{n}=10)\end{array}$ & SEM & $P$-value \\
\hline Apparent total-tract digestibility, \% & 91.6 & 0.69 & 93.0 & 0.74 & 0.13 \\
DM & 88.0 & 1.04 & 89.5 & 1.10 & 0.36 \\
CP & 93.8 & 0.81 & 94.1 & 0.84 & 0.80 \\
Crude fat & 83.2 & 0.13 & 86.2 & 0.13 & 0.14 \\
Crude ash & & & & & \\
Minerals, \% & 77.7 & 0.27 & 81.1 & 0.26 & 0.38 \\
Ca & 84.9 & 0.17 & 87.9 & 0.16 & 0.23 \\
P & 96.7 & 0.62 & 98.8 & 0.37 & 0.02 \\
Na & 97.9 & 0.25 & 98.5 & 0.23 & 0.13 \\
K & & & & & \\
\hline
\end{tabular}

Table 4. Urinary recovery of lactulose and Cr-EDTA and serum concentrations of lactulose, D-mannitol, and Cr-EDTA (LSM) after an oral dose of the markers in calves fed the milk replacer treatments

\begin{tabular}{|c|c|c|c|c|c|}
\hline \multirow[b]{2}{*}{ Item } & \multicolumn{4}{|c|}{ Treatment } & \multirow[b]{2}{*}{$P$-value } \\
\hline & $\begin{array}{l}\text { High fat } \\
(\mathrm{n}=18)\end{array}$ & SEM & $\begin{array}{l}\text { High lactose } \\
\quad(\mathrm{n}=14)\end{array}$ & SEM & \\
\hline \multicolumn{6}{|l|}{0 - to 6-h urine collection } \\
\hline Cr-EDTA, $\%$ of dose & 1.05 & 0.13 & 0.94 & 0.11 & 0.41 \\
\hline Lactulose, $\%$ of dose & 0.70 & 0.08 & 0.55 & 0.07 & 0.95 \\
\hline \multicolumn{6}{|l|}{0 - to 24 -h urine collection } \\
\hline Cr-EDTA, $\%$ of dose & 4.59 & 0.25 & 3.31 & 0.03 & $<0.01$ \\
\hline Lactulose, $\%$ of dose & 2.26 & 0.16 & 1.42 & 0.14 & $<0.01$ \\
\hline \multicolumn{6}{|l|}{ Serum concentration } \\
\hline Cr-EDTA, mg/L & 0.31 & 0.01 & 0.22 & 0.01 & $<0.01$ \\
\hline Lactulose:D-mannitol ratio & 0.85 & 0.05 & 0.66 & 0.04 & 0.01 \\
\hline
\end{tabular}


calves, although a treatment $\times$ time interaction was not detected (Table 4$)$. There was a treatment $\times$ time interaction for fecal scores $(P<0.05$; Figure 1$)$. In wk $1,3,8$, and 9 , HF had fewer abnormal fecal scores than HL.

\section{DISCUSSION}

The main objective of this experiment was to study the effects of dietary energy source (fat vs. lactose) on growth performance, intestinal permeability, digestibility, and fecal consistency in rearing calves. In the current study, BW and ADG were unaffected by CMR composition, likely as a result of the equal total dietary energy and CP intakes. In the study of Tikofsky et al. (2001), different ratios of dietary fat and lactose were tested in dairy calves fed under isocaloric and isonitrogenous conditions, and rates of BW and empty BW gain were not different among treatments. Other studies have shown that increased fat and ME intake from CMR resulted in no change or reduced ADG (Bascom et al., 2007; Hill et al., 2009; Esselburn et al., 2013), although it can be expected that higher inclusion of fat in CMR would have increased fat deposition (Tikofsky et al., 2001; Bascom et al., 2007). However, a limitation of the present study is that body composition measurements were not included in the design. Because a fixed amount of CMR was provided in both treatments, all calves had a similar daily CMR intake (as DM), and for that reason the HF group consumed more fat and therefore more energy from the CMR. However, starter intake postweaning was affected by a treatment $\times$ week interaction $(P<0.05)$, where HL calves consumed more starter in wk $6,7,8$, and 9 . Therefore, both treatments had similar total energy intake over the course of the

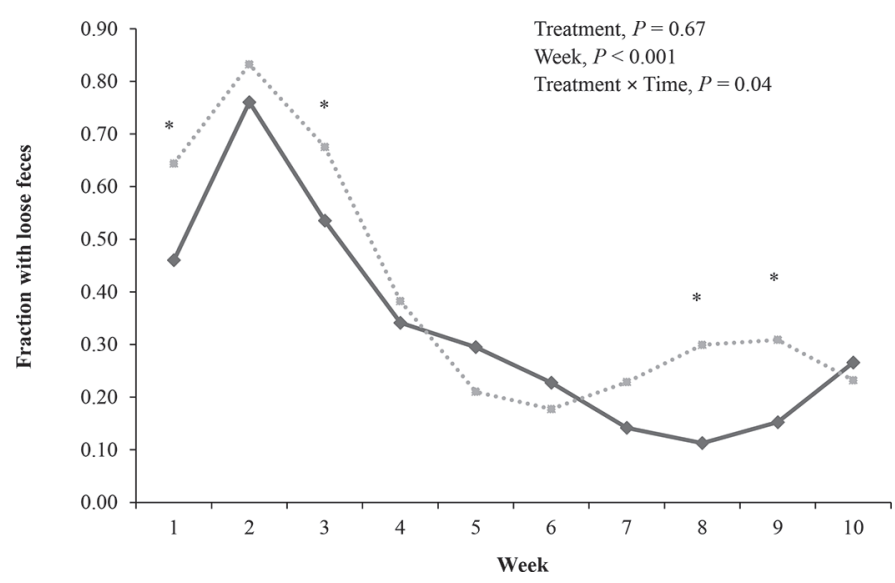

Figure 1. The effect of exchanging fat for lactose in a calf milk replacer on fraction with loose feces of 52 calves fed a high-fat (solid) or a high-lactose (dashed) calf milk replacer. ${ }^{*} P<0.05$. study period. In the study of Kuehn et al. (1994), calves were fed a $20 \%$ CP CMR containing either 15.6 or $21.6 \%$ fat and a texturized calf starter and report that the higher fat in CMR depressed starter intake before and after weaning. Preweaned calves gained more BW with the lower fat CMR, which is in contrast to the current study, where no effect was observed on preweaning gain or BW. To examine the effect of fat inclusion in CMR, Hill et al. (2009) used 48 Holstein calves fed $0.66 \mathrm{~kg} / \mathrm{d}$ DM of CMR containing 14, 17, 20, or $23 \%$ fat and $27 \%$ $\mathrm{CP}$. They concluded that preweaning starter intake responded quadratically to level of fat, being lowest at 14 and $23 \%$ fat in CMR. In contrast, we report here that a numerical increase in starter intake in calves fed the HL CMR was enough to sustain an equal growth rate between groups.

Despite similar intakes of CMR and starter during the week in which apparent total-tract digestibility was measured, there were numerical differences in nutrient digestibility in the HL group compared with the HF group. In the study comparing fat inclusion in CMR, Hill et al. (2009) determined apparent total-tract digestibility on d 19 to 23 and found that DM and fat digestibility decreased linearly as the concentration of fat increased in the CMR. Differences between these studies could be attributed to the fatty acid profile of the fat sources, as in our study the source of fat was palm and coconut oil, whereas the formulations reported in Hill et al. (2009) were based on lard, which has a higher SFA content.

The lactulose-D-mannitol and Cr-EDTA permeability tests were used in parallel for noninvasive monitoring of the mucosal integrity of the small intestine. These noninvasive tests are based on the ability of these molecules to permeate the intestinal mucosa. For large molecules (lactulose and Cr-EDTA), transport is paracellular and therefore takes place through the tight junctions. In contrast, smaller molecules such as mannitol are mostly absorbed transcellularly through epithelial cells by active or passive transport (Wijtten et al., 2011).

Branco Pardal et al. (1995) assessed the intestinal permeability to markers, including lactulose D-mannitol and Cr-EDTA, in calves fed various milk replacers containing skim milk powder, whey, or soy protein. In this experiment, gastrointestinal permeability was assessed in 6 Holstein male calves. The authors showed that urinary lactulose recovered over a 6 -h collection period was between 2.2 and $3.1 \%$ of the dose, depending on the treatment applied. In contrast, our recoveries were substantially lower $(0.5 \pm 0.07$ for HL and $0.7 \% \pm 0.08$ for HF). This difference may be explained by the fact that calves in the study of Branco Pardal et al. (1995) were fed a diet containing antigenic components, which have been associated with impaired intestinal functions 
and digestive disorders (Lallès et al., 1998). Our results are in the range of those reported by Klein et al. (2007), where 24 healthy calves at $10 \mathrm{~d}$ of age fed WM presented a urinary lactulose recovery of $0.58 \%$ over 6 $\mathrm{h}$. Changes in gastrointestinal permeability to markers occur in response to physiological, pharmaceutical, and nutritional stimuli (Branco Pardal et al., 1995; Klein et al., 2007). Dietary fat (7\% soybean oil and $23 \%$ lard) has been shown to increase small intestinal permeability to Cr-EDTA in rats (Suzuki and Hara, 2010). This increase was attributed to the suppression of tight junction protein expression (claudin-1, claudin-3, and occluding; Suzuki and Hara, 2010).

Results for serum lactulose:D-mannitol ratio and serum Cr-EDTA were consistent with urine results and showed higher values in calves fed $\mathrm{HF}$ at $60 \mathrm{~min}(1.1 \pm$ 0.06 and $0.9 \pm 0.06$, respectively; data not shown). As shown by Araujo et al. (2015), a high serum ratio (1.26 $\pm 0.16)$ is indicative of compromised gut barrier function, which may be more permeable to large molecules. However, in each of the 2 experiments, the assessment was performed on diarrheic calves and might therefore not be relevant to the current study, where healthy calves were used to determine differences in energy source on gastrointestinal permeability.

Despite there being no differences in performance or nutrient digestibility, the higher marker recovery is suggestive of an increase in gastrointestinal permeability in calves fed HF. In rodents and humans, dietary fat has been associated with decreased intestinal integrity, mainly in the context of postprandial endotoxemia (Boutagy et al., 2016). Intestine-derived LPS can be incorporated into micelles and chylomicrons (due to its insoluble component lipid A) and absorbed along lipids, transiently increasing its appearance in blood (Boutagy et al., 2016). Nevertheless, changes in intestinal integrity in adult humans have only been associated with dietary fat in the context of very high fat diets, and whether this occurs under physiological consumptions remains controversial (Vors et al., 2015). In the current study, the milk fat concentration in the HF diet was established to be similar to WM, and thus it is unlikely that dietary lipids had a major detrimental effect on gastrointestinal health. In agreement with this, none of the measured parameters (performance, nutrient digestibility, feces score, or diarrhea incidence) were negatively affected by HF. Reasons for the observed increase in marker recovery are currently not clear. We speculate that because markers were diluted with the dietary treatments, there could have been an interaction with milk fat (similar to what happens with LPS), thereby increasing their absorption. The effect of separating the marker from the diet (Klein et al.,
2007) in a milk-fed preruminant model remains to be addressed.

The diet with HF had a lower frequency of abnormal fecal scores at 2 times points: in the first weeks (1-3 wk) and around the weaning period (8-9 wk). This could be associated with level of lactose, which increases the osmolality of CMR. This parameter can range from slightly hypertonic (just above $300 \mathrm{mOsm} /$ $\mathrm{kg})$ to highly hypertonic $(>450 \mathrm{mOsm} / \mathrm{kg}$; Wilms et al., 2019). Hypertonic solutions have been associated with delayed abomasal emptying rate (Bell and Razig, 1973; Sen et al., 2006), which was shown to increase the incidence of gastrointestinal diseases in calves such abomasal bloat (Glenn Songer and Miskimins, 2005) and diarrhea (Foster and Smith, 2009). Moreover, lactose intakes exceeding nutritional tolerance increase the incidence of gastrointestinal dysfunction in the first 4 wk of age, referred to as "nutritional diarrhea" (Hof, 1980). In the weaning period beginning in wk $7, \mathrm{HF}$ calves had fewer abnormal fecal scores than HL calves. A possible explanation was the weaning stress due to differences in ME content and subsequent CMR energy intake. Energy shortage can depress immune function and increase susceptibility to diseases in calves (Nonnecke et al., 2003).

\section{CONCLUSIONS}

A weight-weight exchange of lactose for fat does not affect calf growth and performance, total starter intake, or apparent total digestion of macronutrients. High-fat CMR was associated with an increase in permeability indicators with a corresponding improvement in fecal scores. The effect of high-fat CMR formulations on intestinal health remains to be further elucidated.

\section{ACKNOWLEDGMENTS}

The authors thank Natasja Boots, Mieke LangenThijssen, and the staff of the Trouw Nutrition Calf and Beef Research facility (Amersfoort, the Netherlands) for their skilled technical assistance.

\section{REFERENCES}

Araujo, G., and A. Bach. 2015. Feeding strategies to improve performance and health of Holstein calves. PhD Thesis. Universitat Autonoma de Barcelona, Bellaterra, Spain.

Araujo, G., C. Yunta, M. Terré, A. Mereu, I. Ipharraguerre, and A. Bach. 2015. Intestinal permeability and incidence of diarrhea in newborn calves. J. Dairy Sci. 98:7309-7317.

Bach, A. 2012. Ruminant Nutrition Symposium: Optimizing performance of the offspring: Nourishing and managing the dam and postnatal calf for optimal lactation, reproduction, and immunity. J. Anim. Sci. 90:1835-1845. 
Bartlett, K. S., F. K. McKeith, M. J. VandeHaar, G. E. Dahl, and J. K. Drackley. 2006. Growth and body composition of dairy calves fed milk replacers containing different amounts of protein at two feeding rates. J. Anim. Sci. 84:1454-1467.

Bascom, S. A., R. E. James, M. L. McGilliard, and M. E. Van Amburgh. 2007. Influence of dietary fat and protein on body composition of Jersey bull calves. J. Dairy Sci. 90:5600-5609.

Bell, F. R., and S. A. D. Razig. 1973. Gastric emptying and secretion in the milk-fed calf. J. Physiol. 228:499-512.

Boutagy, N. E., R. P. McMillan, M. I. Frisard, and M. W. Hulver. 2016. Metabolic endotoxemia with obesity: Is it real and is it relevant? Biochimie 124:11-20.

Branco Pardal, P., J. P. Lallés, F. André, E. Delval, and R. Toullec. 1995. Assessment of gastrointestinal permeability to small marker probes in the preruminant calf. Reprod. Nutr. Dev. 35:189-200.

Brown, E. G., M. J. VandeHaar, K. M. Daniels, J. S. Liesman, L. T. Chapin, D. H. Keisler, and M. S. Weber Nielsen. 2005. Effect of increasing energy and protein intake on body growth and carcass composition of heifer calves. J. Dairy Sci. 88:585-594.

Drackley, J. K. 2008. Calf nutrition from birth to breeding. Vet. Clin. North Am. Food Anim. Pract. 24:55-86.

EC. 2009. No 152/2009. Commission regulation laying down the methods of sampling and analysis for the official control of feed. Off. J. Eur. Union L 54:1-130.

Esselburn, K. M., K. M. O'Diam, T. M. Hill, H. G. Bateman II, J. M. Aldrich, R. L. Schlotterbeck, and K. M. Daniels. 2013. Intake of specific fatty acids and fat alters growth, health, and titers following vaccination in dairy calves. J. Dairy Sci. 96:5826-5835.

Etheridge, R., G. Pesti, and E. Foster. 1998. A comparison of nitrogen values obtained utilizing the Kjeldahl nitrogen and Dumas combustion methodologies (Leco CNS 2000) on samples typical of an animal nutrition analytical laboratory. Anim. Feed Sci. Technol. 73:21-28.

European Union. 2017. NEN-EN 15510. Animal feeding stuffs: Methods of sampling and analysis - Determination of calcium, sodium, phosphorus, magnesium, potassium, iron, zinc, copper, manganese, cobalt, molybdenum and lead by ICP-AES. Official Journal of the European Union.

Foster, D. M., and G. W. Smith. 2009. Pathophysiology of diarrhea in calves. Vet. Clin. North Am. Food Anim. Pract. 25:13-36.

Glenn Songer, J. G., and D. W. Miskimins. 2005. Clostridial abomasitis in calves: Case report and review of the literature. Anaerobe 11:290-294.

Hill, S. R., K. F. Knowlton, K. M. Daniels, R. E. James, R. E. Pearson, A. V. Capuco, and R. M. Akers. 2008. Effects of milk replacer composition on growth, body composition, and nutrient excretion in preweaned Holstein heifers. J. Dairy Sci. 91:3145-3155.

Hill, T. M., H. G. Bateman II, J. M. Aldrich, and R. L. Schlotterbeck. 2009. Effect of fat concentration of a high-protein milk replacer on calf performance. J. Dairy Sci. 92:5147-5153.

Hill, T. M., H. G. Bateman, J. M. Aldrich, and R. L. Schlotterbeck. 2010. Effect of milk replacer program on digestion of nutrients in dairy calves. J. Dairy Sci. 93:1105-1115.

Hof, G. 1980. An investigation into the extent to which various dietary components, particularly lactose, are related to the incidence of diarrhoea in milk-fed calves. PhD Thesis. Wageningen University, Wageningen, the Netherlands.

Klein, P., J. Moravcová, T. Kleinová, Z. Volek, and V. Skrivanová. 2007. Assessment of intestinal permeability in preruminant calves by lactulose/mannitol test. J. Anim. Feed Sci. 16:43-52.

Kuehn, C. S., D. E. Otterbv, J. G. Linn, W. G. Olson, H. ChesterJones, G. D. Marx, and J. A. Barmore. 1994. The effect of dietary energy concentration on calf performance. J. Dairy Sci. 77:26212629 .
Lallès, J. P., C. Duvaux-Ponter, J. W. Sissons, and R. Toullec. 1998. Small intestinal motility disorders in preruminant calves chronically fed a diet based on antigenic soya: Characterization and possible mediators. Vet. Res. 29:59-72.

Lee, H. J., M. A. Khan, W. S. Lee, S. H. Yang, S. B. Kim, K. S. Ki, H. S. Kim, J. K. Ha, and Y. J. Choi. 2009. Influence of equalizing the gross composition of milk replacer to that of whole milk on the performance of Holstein calves. J. Anim. Sci. 87:1129-1137.

Moallem, U., D. Werner, H. Lehrer, M. Zachut, L. Livshitz, S. Yakoby, and A. Shamay. 2010. Long-term effects of ad libitum whole milk prior to weaning and prepubertal protein supplementation on skeletal growth rate and first-lactation milk production. J. Dairy Sci. 93:2639-2650.

National Animal Health Monitoring Service (NAHMS). 2007. Dairy 2007. Heifer calf health and management practices on U.S. dairy operations. USDA-APHIS-VS. 62. Accessed Feb. 12, 2018. http: //www.aphis.usda.gov/animal_health/nahms/dairy/downloads/ dairy07/Dairy07_ir_CalfHealth.pdf.

National Research Council. 2001. Nutrient Requirements of Dairy Cattle. 7th rev. ed. Natl. Acad. Press, Washington, DC

Nonnecke, B. J., M. R. Foote, J. M. Smith, B. A. Pesch, and M. E. Van Amburgh. 2003. Composition and functional capacity of blood mononuclear leukocyte populations from neonatal calves on standard and intensified milk replacer diets. J. Dairy Sci. 86:35923604 .

Park, Y. W. 2009. Bioactive Components in Milk and Dairy Products. Wiley-Blackwell, Ames, IA.

Rijnen, M. M. J. A., M. W. A. Verstegen, M. J. W. Heetkamp, and J. W. Schrama. 2001. Effects of dietary fermentable carbohydrates on energy metabolism in group-housed sows. J. Anim. Sci. 79:148154.

Sen, I., P. D. Constable, and T. S. Marshall. 2006. Effect of suckling isotonic or hypertonic solutions of sodium bicarbonate or glucose on abomasal emptying rate in calves. Am. J. Vet. Res. 67:13771384 .

Shamay, A., D. Werner, U. Moallem, H. Barash, and I. Bruckental. 2005. Effect of nursing management and skeletal size at weaning on puberty, skeletal growth rate, and milk production during first lactation of dairy heifers. J. Dairy Sci. 88:1460-1469.

Silva, A. L., M. I. Marcondes, E. Detmann, F. S. Machado, S. C. Valadares Filho, A. S. Trece, and J. Dijkstra. 2015. Effects of raw milk and starter feed on intake and body composition of Holstein $\times$ Gyr male calves up to 64 days of age. J. Dairy Sci. 98:2641-2649.

Soberon, F., E. Raffrenato, R. W. Everett, and M. E. Van Amburgh. 2012. Preweaning milk replacer intake and effects on long-term productivity of dairy calves. J. Dairy Sci. 95:783-793.

Suzuki, T., and H. Hara. 2010. Dietary fat and bile juice, but not obesity, are responsible for the increase in small intestinal permeability induced through the suppression of tight junction protein expression in LETO and OLETF rats. Nutr. Metab. (Lond.) 7:19.

Tikofsky, J. N., M. E. Van Amburgh, and D. A. Ross. 2001. Effect of varying carbohydrate and fat content of milk replacer on body composition of Holstein bull calves. J. Anim. Sci. 79:2260-2267.

Vors, C., G. Pineau, J. Drai, E. Meugnier, S. Pesenti, M. Laville, F. Laugerette, C. Malpuech-Brugère, H. Vidal, and M.-C. Michalski. 2015. Postprandial endotoxemia linked with chylomicrons and lipopolysaccharides handling in obese versus lean men: A lipid doseeffect trial. J. Clin. Endocrinol. Metab. 100:3427-3435.

Wijtten, P. J. A., J. van der Meulen, and M. W. A. Verstegen. 2011. Intestinal barrier function and absorption in pigs after weaning: A review. Br. J. Nutr. 105:967-981.

Wilms, J., H. Berends, and J. Martín-Tereso. 2019. Hypertonic milk replacers increase gastrointestinal permeability in healthy dairy calves. J. Dairy Sci. https://doi.org/10.3168/jds.2018-15265. 